\title{
A "INTOXICAÇÃO SEXUAL" DO NOVO MUNDO: SEXUALIDADE E PERMISSIVIDADE NO LIVRO CASA-GRANDE \& SENZALA
}

\author{
Moisés Alessandro de Souza Lopes \\ Mestrando em Ciências Sociais na UEL \\ E-mail: sepolm@hotmail.com
}

\section{Resumo}

O presente artigo explora o movimento de construção da sexualidade no Brasil pautado na análise da obra Casa-Grande \& Senzala de Gilberto Freyre. O foco central da discussão é a contribuição do movimento de miscigenação - dos três povos que formam a base da população brasileira - bem como, do processo de colonização do português no Brasil para a estruturação de uma sexualidade pautada pela permissividade, em determinados momentos e, pelo patriarcalismo, em outros. Além disso, busco analisar a permanência de alguns traços dessa sexualidade (permissiva/patriarcal) na atualidade.

Palavras-chave: miscigenação; sexualidade; permissividade; patriarcalismo.

ste é um texto sobre a sexualidade brasileira lida na obra CasaGrande \& Senzala de Gilberto Freyre. Longe de buscar resgatar ou mesmo esgotar toda a discussão sobre este tema tão rico em uma obra tão vasta, este artigo tem, no entanto, a pretensão de oferecer alguns subsídios para diversas leituras possíveis desta obra no que tange à vida sexual brasileira.

Digo diversas leituras pois, muito se têm criticado alguns aspectos da obra Casa-Grande \& Senzala seja pelo estilo literário seja pela exaltação da miscigenação que resultaria na criação, posteriormente, da 
idéia de uma democracia racial. Nas palavras de Darcy Ribeiro expressas no prefácio critico da própria obra, "Gilberto Freyre escreveu, de fato, a obra mais importante da cultura brasileira" (FREYRE, 2000, p.11)

Mas por que essa obra assume tamanha importância para a cultura do Brasil? Casa-Grande \& Senzala é um livro que revolucionou os estudos no Brasil tanto pela novidade dos conceitos quanto pela qualidade literária. Gilberto Freyre partiu do estudo das relações entre os senhores de engenho e os escravos. Para tal, foi buscar nos diários dos senhores de engenho e na vida pessoal de seus próprios antepassados a história da cultura brasileira. Para Darcy Ribeiro (apud FREYRE, 2000, p.12),

\begin{abstract}
Casa-Grande \& Senzala é, sem dúvida, uma façanha da cultura brasileira, como aliás foi visto desde os primeiros dias. Para Jorge Amado, o surgimento de CG\&S foi uma explosão de deslumbramento. Desde alguns anos antes, observa ele, vinham surgindo os primeiros romances regionais que buscavam laboriosamente restabelecer a verdade sobre a vida social brasileira, falsificada pela literatura tradicionalista. Mas um livro de estudos do Brasil, que fosse legível, bem escrito como Casa-Grande $\&$ Senzala, era coisa nunca vista [...].
\end{abstract}

Assim, partindo desse livro, busco mostrar como a miscigenação e o patriarcalismo fizeram surgir no Brasil formas específicas de organização da vida sexual, de definição dos papéis sexuais de masculinidade e feminilidade, noções do que foi, e ainda hoje é, ser homem em oposição à mulher na sociedade brasileira.

Para atingir tal intuito dividi este texto em quatro partes. $\mathrm{Na}$ primeira, explicito as características fundamentais e a especificidade da colonização portuguesa e analiso como a miscigenação através da sexualidade se tornou uma política de aumento populacional para ocupação do território ainda inexplorado. No fragmento seguinte intitulado "Permissividade e sexualidade na colonização do Brasil" ressalto como a permissividade e o patriarcalismo influenciaram na formação da sexualidade brasileira, bem como na formação dos papéis de homem e mulher. Na terceira parte, "Casa-Grande \& Senzala Hoje" busco algumas permanências na atualidade das concepções de sexualidade e papéis 
sexuais elencadas por Gilberto Freyre em sua obra. Já na última parte traço algumas considerações finais.

\section{Miscigenação e Sexualidade na Colonização do Brasil}

Segundo Richard Parker (1991), no século XIX, após a declaração de independência, surge uma preocupação crescente com a identidade nacional e começam a emergir interpretações baseadas na miscigenação das três raças (européia, ameríndia e africana) como algo importante na formação do povo brasileiro. A mistura das três raças através da sexualidade como constituição histórica do brasileiro tornase um mito de origem. Seyferth (1996) reforça essa análise ao afirmar que no Brasil essa preocupação torna-se foco inclusive de políticas imigratórias com o intuito de "branquear" a população nacional, mas também relacionada com a necessidade de ocupação do território,

[...] a miscigenação se transformou em assunto privilegiado no discurso nacionalista brasileiro após 1850 , vista como mecanismo de formação da nação desde os tempos coloniais e base de uma futura raça histórica brasileira, de um tipo nacional, resultante de um processo seletivo direcionado para o branqueamento da população (SEYFERTH,1996, p.43).

O surgimento da idéia de branqueamento da população nacional se pautou pela emergência da noção de raça e pela premissa de uma desigualdade marcante entre estas raças. Segundo Seyferth (1996, p.43), as teorias de raça do século XIX tinham em comum,

[...] o dogma de que a diversidade humana, anatômica e cultural, era produzida pela desigualdade das raças; e a partir deste dogma, produziram-se hierarquias raciais que invariavelmente localizavam os europeus civilizados no topo, os negros 'bárbaros' e os indios 'selvagens' se revezando na base, e todos os demais ocupando as posições intermediárias.

Assim, durante todo o século XIX e parte do XX a mestiçagem adquiriu um aspecto negativo, representando a decadência das civili- 
zações. No Brasil autores como Nina Rodrigues, Paulo Prado, Alberto Torres, Oliveira Viana entre outros, apontam o mestiçamento como fator de inferioridade racial do brasileiro. Gilberto Freyre adentra esse debate promovendo uma recusa das teses baseadas em determinismos raciais e distinguindo raça de cultura em suas análises1. Assim, entra em choque com estes diversos autores brasileiros e estrangeiros, bem como com a elite, que viam na mistura de raça um evento que promovia a degradação do branco e a incapacidade do povo brasileiro para alcançar o desenvolvimento.

O autor de Casa-Grande \& Senzala busca analisar de um ponto de vista mais positivo a mistura de raças e a criação de uma nova civilização nos trópicos, como resultado dessa mistura que deixou suas marcas não somente nos corpos dos brasileiros, mas também na alma brasileira. Para este autor, a mistura racial não é entendida apenas como elemento unificador da vida brasileira, mas também fornece aos brasileiros o potencial para criar através da fusão das três culturas (ameríndia, africana e européia), uma civilização distinta.

Gilberto Freyre aponta a miscigenação como um fenômeno necessário para o povoamento da colônia, afirmando que após o século XVII ocorre um maior número de casamentos entre os portugueses e as caboclas ou índias e a formação de uma estrutura colonial baseada na estrutura familiar. De acordo com o autor,

\begin{abstract}
A luxúria dos indivíduos, soltos sem família, no meio da indiada nua, vinha servir a poderosas razões de Estado no sentido de rápido povoamento mestiço da nova terra. E o certo é que sobre a mulher gentia fundou-se e desenvolveu-se através dos séculos XVI X XVII o grosso da sociedade colonial, num largo e profundo mestiçamento, que a interferência dos padres da Companhia salvou de resolver-se todo em libertinagem para em grande parte regularizar-se em casamento (FREYRE, 2000, p.164).
\end{abstract}

Segundo Gilberto Freyre, o Estado português solucionou o problema de escassez populacional para colonizar novas terras através da

\footnotetext{
A distinção entre raça e cultura, absorvida de Franz Boas, se torna o eixo de onde emerge toda a reflexão de Gilberto Freyre sobre o Brasil na obra CasaGrande \& Senzala.
} 
miscigenação, transformando o mestiçamento em verdadeira "instituição pública". Com esta política de miscigenação, o povo português acabou por se adaptar totalmente à região dos trópicos diferenciandose dos outros europeus que tentaram colonizar regiões aqui. Nas palavras do autor,

A falta de gente, que $o$ afligia, mais do que a qualquer outro colonizador, forçando-o à imediata miscigenação - contra o que não indispunham, aliás, escrúpulos de raça, apenas preconceitos religiosos - foi para o português vantagem na sua obra de conquista e colonização dos trópicos. Vantagem para a sua melhor adaptação, senão biológica, social (FREYRE, 2000, p.87).

Além disso, no Brasil ocorria uma enorme escassez de mulheres brancas o que não permitia a constituição de uma aristocracia eminentemente portuguesa. Ainda de acordo com Freyre (2000, p.255), "independente da falta ou escassez de mulher branca o português sempre pendeu para o contato voluptuoso com mulher exótica". Esta tendência do povo português resulta de uma maior plasticidade social deste povo do que de qualquer outro colonizador europeu.

Freyre traça um paralelo entre os colonizadores do Brasil e os demais colonizadores das Américas com o objetivo de mostrar a especificidade do povo que colonizou e que habitava este país. Para ele, os espanhóis e os ingleses evocavam a moral católica e a consciência de raça para afastar a miscigenação e o paganismo. Já os portugueses, continua o autor, eram menos ortodoxos que os espanhóis e menos carregados de preconceitos de cor e moral cristã que os ingleses:

Quanto à miscibilidade, nenhum povo colonizador, dos modernos, excedeu ou sequer igualou nesse ponto aos portugueses. Foi misturando-se gostosamente com mulheres de cor logo ao primeiro contato e multiplicando-se em filhos mestiços que uns milhares apenas de machos atrevidos conseguiram firmar-se na posse de terras vastíssimas e competir com povos grandes e numerosos na extensão de domínio colonial e na eficácia de ação colonizadora. A miscibilidade, mais do que a mobilidade, foi o processo pelo qual os portugueses compensaram-se da deficiência em massa ou volume humano para a colonização em larga escala e sobre áreas extensíssimas. Para tal processo preparara- 
os a íntima convivência, o intercurso social e sexual com raças de cor, invasora ou vizinhas na península, uma delas, a de fé maometana, em condições superiores, técnicas e de cultura intelectual e artística, à dos cristãos louros (FREYRE, 2000, p.84).

Para explicar a falta de sentimento ou consciência de raça, Freyre recorre à história da formação do povo da Península Ibérica e demonstra que a formação do povo português é marcada pela heterogeneidade de cultura e contato com diversos povos que conquistaram e habitaram esta península. Dentre estes contatos o autor cita aqueles com os mouros, os castelhanos e os judeus como fundamentais para entender a cultura portuguesa. Além deste fator, a análise freyreana aponta os contatos cosmopolitas por via marítima, a situação geográfica e as condições de meio físico de Portugal como fatores que influenciaram a formação do povo português. Assim se expressa Gilberto Freyre (p.102-103):

O perigo não estava no estrangeiro nem no indivíduo disgênico ou cacogênico, mas no herege. [...] temia-se no adventício acatólico o inimigo político capaz de quebrar ou de enfraquecer aquela solidariedade que em Portugal se desenvolvera junto com a religião católica. Essa solidariedade manteve-se entre nós esplendidamente através de toda a nossa formação colonial reunindo-nos contra os calvinistas franceses, contra os reformadores holandeses, contra os protestantes ingleses. Daí ser tão difícil, na verdade, separar o brasileiro do católico: o catolicismo foi realmente o cimento da nossa unidade.

O colonizador português aceitava que indivíduos de qualquer nacionalidade viessem para o Brasil desde que fossem católicos. O catolicismo, marcado sempre pela luta de fiéis contra infiéis, de cristãos contra hereges, tornou-se o fator unificador do território, pois para adquirir terras no Brasil era necessário professar a fé católica. A fé torna-se a condição para ser aceito no Brasil e não a nacionalidade. Mas, adverte Gilberto Freyre, a moral cristã católica do português tinha suas especificidades, pois havia sido afetada pelo contato com os povos árabes, principalmente os mouros que eram polígamos. A moral sexual católica portuguesa tornou-se impregnada de simbolismos pagãos, mais frouxa e menos dura que a dos outros colonizadores das Américas. Afirma o autor: 
Um catolicismo ascético, ortodoxo, entravando a liberdade aos sentidos e aos instintos de geração teria impedido Portugal de abarcar meio mundo com as pernas. As sobrevivências pagãs no cristianismo português desempenharam assim papel importante na política imperialista. As sobrevivências pagã̃ e as tendências para a poligamia desenvolvidas ao contato quente e voluptuoso com os mouros (FREYRE, 2000, p.311).

Essas tendências para a poligamia se "despertam" no português quando da chegada deste colonizador ao Brasil. Aqui ele se depara com uma população nua e com uma liberdade sexual marcada pela livre união entre os indígenas, que apesar de ser um fator contrário à moral católica acaba sendo experimentada pelos primeiros aventureiros e exploradores. Mais tarde com o estabelecimento da monocultura, do latifúndio e da escravidão, o modelo de família patriarcal se cristalizará e se tornará a unidade social dominante, essencial para a integração social e a sociabilização dos indivíduos.

No Brasil, a família patriarcal assumiu um papel importante por se constituir como forma de organização social e também construção ideológica que influencia, ainda hoje, a construção dos papéis de homem e mulher, bem como, as noções de masculinidade e feminilidade e a vida sexual do brasileiro. O modelo clássico de família patriarcal consistia na natureza ilimitada de poder do patriarca baseada na violência (direito à morte inclusive) e na estrutura hierárquica tendo o patriarca, a mulher e os filhos legítimos no núcleo (casa-grande) e as concubinas, amantes, filhos ilegítimos e escravos na periferia deste núcleo, todos ligados e integrados socialmente pelo patriarca. Nas palavras de Gilberto Freyre (2000, p.96),

Todos esses elementos, a começar pelo cristianismo liricamente social, religião ou culto de família mais do que de catedral ou de igreja - que nunca as tiveram portugueses grandes e dominadoras do tipo das de Toledo ou das de Burgos, como nunca as teria o Brasil da mesma importância e prestígio que as da América Espanhola; todos esses elementos e vantagens viriam favorecer entre nós a colonização, que na América Portuguesa, como nas 'colônias de proprietários' dos ingleses na América do Norte, repousaria sobre a instituição família escravocrata; da casa-grande; da família patriarcal; sendo que nestas bandas acrescida a 
família de muito maior número de bastardos e dependentes em torno dos patriarcas, mais femeeiros que os de lá e um pouco mais soltos, talvez, na sua moral sexual.

\section{Permissividade e Sexualidade no Brasil}

$\mathrm{O}$ ambiente em que começou a vida brasileira foi de quase intoxicação sexual. O europeu saltava em terra escorregando em índia nua; os próprios padres da Companhia precisavam descer com cuidado, senão atolavam o pé em carne. Muitos clérigos, dos outros, deixaram-se contaminar pela devassidão. As mulheres eram as primeiras a se entregarem aos brancos, as mais ardentes indo esfregar-se nas pernas desses que supunham deuses. Davam-se ao europeu por um pente ou um caco de espelho (Freyre,2000,p.164).

É assim que Gilberto Freyre descreve a vida sexual brasileira em seus primeiros tempos, marcada por uma excessiva permissividade sexual. No entanto, ele mesmo afirma que esta liberdade sexual não deve ser lida tão sem restrições como propuseram alguns autores, mas que deve ser analisada inserida em seus costumes e cita o exemplo de certas tribos que ofertavam mulheres a seus hóspedes com o intuito de hospitalidade. Para ele, o "que desfigura esses costumes é a má interpretação dos observadores superficiais" (FREYRE, 2000,p.173).

A "intoxicação sexual" do Novo Mundo, inicialmente instalada no contato do colonizador com o colonizado - do português com o ameríndio - abriu o caminho para a integração de um terceiro elemento - o africano - dando surgimento à mistura entre as três raças distintas que iriam definir a natureza da realidade sociocultural brasileira. Entretanto, à miscigenação que uniu estas três raças e à excessiva liberdade sexual soma-se a sífilis como uma desvantagem e uma perturbação ao processo de colonização.

Trazida pelos exploradores europeus, a sífilis teve um impacto no Brasil que dificilmente pode ser separado do momento de contato que iria dar origem à mistura racial no Brasil. Entretanto, a sífilis teve seu maior impacto no Nordeste dos séculos XVII e XVIII. Foi na casa-grande e na senzala, que o reino da sífilis, como o do sexo foi mais intenso. Vejamos: 
A sífilis fez sempre o que quis no Brasil patriarcal. Matou, cegou, deformou à vontade. Fez abortar mulheres. Levou anjinhos para o céu. Uma serpente criada dentro de casa sem ninguém fazer caso de seu veneno. O sangue envenenado rebentava em feridas. Coçavam-se então as perebas ou "cabidelas", tomavam-se garrafadas, chupava-se caju. A sifilização do Brasil admitida sua origem extra-americana - vimos, às primeiras páginas deste trabalho, que data dos princípios do século XVI. Mas no ambiente voluptuoso das casas-grandes, cheias de crias, negrinhas, mulecas, mucamas, é que as doenças venéreas se propagaram mais à vontade, através da prostituição doméstica - sempre menos higiênica que a dos bordéis (FREYRE, 2000,p.374).

Ligada à sensualidade "desenfreada" do passado brasileiro, a sífilis marca o corpo brasileiro, tanto quanto a miscigenação marca a alma. A sífilis assume uma grande importância simbólica no texto de Gilberto Freyre, à medida que desmistifica a idéia de que a degeneração física, atribuída por alguns escritores à mistura de raças e ao clima, aparece agora, na verdade, como produto de infecção sifilítica seguida por um regime alimentar deficiente.

Além disso, Freyre refuta a idéia de que os colonizadores portugueses se tornaram vítimas dos trópicos sedutores e dos nativos ou de negros inferiores culturalmente e envoltos em pecados como o da luxúria. Para o autor,

Foram sexualidades exaltadas a dos dois povos que primeiro se encontraram nesta parte da América; o português e a mulher indígena. Contra a idéia geral de que a lubricidade maior comunicou-a ao brasileiro o africano, parece-nos que foi precisamente este, dos três elementos que se juntaram para formar o Brasil, o mais fracamente sexual; e o mais libidinoso, o português (FREYRE, 2000, p.171).

Na verdade, a sexualidade exacerbada da vida brasileira, depois da chegada do europeu, deve ser relacionada ao meio sócio-econômico no qual estavam inseridas essas raças. Resultado direto das relações de poder e dominação e do sistema de produção econômico que marcou a vida colonial. A escravidão como instituição social torna-se, na análise freyreana, responsável pela frouxidão moral e pelo excesso sexual. Nas palavras do autor, 
É absurdo responsabilizar-se o negro pelo que não foi obra sua nem do índio mas do sistema social e econômico em que funcionaram passiva e mecanicamente. Não há escravidão sem depravação sexual. É da essência mesma do regime. Em primeiro lugar, o próprio interesse econômico favorece a depravação criando nos proprietários de homens imoderado desejo de possuir o maior número possível de crias. Joaquim Nabuco colheu num manifesto escravocrata de fazendeiros as seguintes palavras, tão ricas de significação: 'a parte mais produtiva da propriedade escrava é o ventre gerador'(FREYRE, 2000, p.372).

Longe de ser o produto da degeneração de um povo mestiço, o caráter extremamente sexualizado (e, conseqüentemente, sifilizado) da vida brasileira estava ligado não à miscigenação em si, mas ao contexto social que a produziu. Para reforçar isso, Freyre traça um paralelo entre o sistema escravista fundado no Brasil e o estabelecido no Sul dos Estados Unidos afirmando que tanto em um lugar como no outro é na essência da própria instituição escravidão que está ligada à depravação sexual. E é nesse ambiente marcado pela depravação sexual que ocorrerá a sifilização tanto da casa-grande quanto da senzala:

O intercurso sexual entre o conquistador europeu e a mulher índia não foi apenas perturbado pela sífilis e por doenças européias de fácil contágio venéreo: verificou-se - o que depois se tornaria extensivo às relações dos senhores com as escravas negras - em circunstâncias desfavoráveis à mulher. Uma espécie de sadismo do branco e de masoquismo da índia ou da negra terá predominado nas relações sexuais como nas sociais do europeu com as muiheres das raças submetidas ao seu domínio. $\mathrm{O}$ furor femeeiro do português se terá exercido sobre vítimas nem sempre confraternizantes no gozo; ainda que se saiba de casos de pura confraternização do sadismo do conquistador branco com o masoquismo da mulher indígena ou da negra. Isso quanto ao sadismo de homem para mulher - não raro precedido pelo de senhor para muleque. Através da submissão do muleque, seu companheiro de brinquedos e expressivamente chamado levapancadas, iniciou-se muitas vezes o menino branco no amor físico (FREYRE, 2000,p.121-122).

$\mathrm{Na}$ intimidade da casa-grande, os meninos eram iniciados sexualmente pela escrava negra, pelo "leva-pancadas" ou mesmo pelo abu- 
so de animais como vacas, cabras, ovelhas, galinhas; ou ainda pelo uso de plantas e frutas, tais como a bananeira, a fruta do mandacaru, a melancia. Os meninos no Brasil teriam sua vida sexual antecipada pelas negras que passariam a vigorar como verdadeiras corruptoras da moral familiar, bem como, pelo clima tropical. Para desmistificar esta assertiva, Freyre afirma que essa antecipação sexual dos meninos era inclusive estimulada pelos pais, e pelo sistema escravocrata, como já dito anteriormente. Assim se expressa o autor:

A verdade, porém, é que nós é que fomos os sadistas; o elemento ativo na corrupção da vida de família; e muleques e mulatas o elemento passivo. Na realidade, nem o branco nem o negro agiram por si, muito menos como raça, ou sob a ação preponderante do clima, nas relações de sexo e de classe que se desenvolveram entre senhores e escravos no Brasil. Exprimiu-se nessas relações o espírito do sistema econômico que nos dividiu, como um deus poderoso, em senhores e escravos. Dele se deriva a exagerada tendência para o sadismo característica do brasileiro, nascido e criado em casa-grande, principalmente em engenho; $\mathrm{e}$ a que insistentemente temos aludido neste ensaio (FREYRE, 2000, p.430-431).

Essa prostituição doméstica era incentivada pelo sistema escravocrata para a "produção" de um maior número de escravos. Freyre chega a falar em degradação das raças atrasadas pelo domínio da raça adiantada. Pois, esta acabou reduzindo os indígenas e os escravos ao cativeiro e à prostituição. Além disso, o sistema escravista colocava $o$ senhor em uma situação de extremo ócio, que passava a ser ocupado com a libertinagem. Freyre (2000, p.482) afirma:

Ociosa, mas alagada de preocupações sexuais, a vida do senhor de engenho tornou-se uma vida de rede. Rede parada, com o senhor descansando, dormindo, cochilando. Rede andando, com o senhor em viagem ou passeio debaixo de tapetes ou cortinas. Rede rangendo, com o senhor copulando dentro dela. Da rede não precisava afastar-se 0 escravocrata para dar as suas ordens aos negros; [...].

Já as mulheres, em oposição a essa extrema liberdade sexual dos meninos e dos homens, tinham uma sexualidade reprimida tanto pelos 
pais quanto posteriormente pelos maridos e, quando fugiam a essa repressão, podiam inclusive ser mortas. Devido ao sistema patriarcal, eram mantidas em uma posição inferior à do homem e deveriam ter uma atitude quase servil em relação ao marido. Tinham uma vida marcada pelo casamento cedo e sempre com homens muito mais velho, conforme enfatiza Freyre (2000, p.475): “As meninas criadas em ambiente rigorosamente patriarcal, estas viveram sob a mais dura tirania dos pais - depois substituída pela tirania dos maridos".

Tendo o poder investido em suas mãos, o homem era caracterizado em termos de superioridade, força, virilidade, atividade, potencial de violência e legítimo uso da força. Contrariamente, temos a mulher, inferiorizada, fragilizada, desejada e bela, mas sempre sujeita à dominação do patriarca. Esse padrão duplo de moralidade - homem com liberdade sexual e mulher com atividade sexual regulada e controlada - gerou comportamentos e espaços distintos para homens e mulheres, respectivamente, engenho e casa, cidade/rua e casa, ação e inação, atividade e passividade.

\section{Casa-Grande \& Senzala Hoje}

Esta análise empreendida da obra Casa-Grande \& Senzala fez emergir inquietantes questões. Como essa tradição patriarcal e essa sexualidade extremada são significadas contemporaneamente? Como esse patriarcalismo e essa permissividade influem (se influem) ainda hoje para a construção dos papéis sexuais feminino e masculino (de macho e fêmea) na sociedade brasileira? Para responder a estas questões me remeterei à análise desenvolvida por Richard Parker, em seu livro "Corpos, Prazeres e Paixões", sobre a cultura sexual contemporânea no Brasil.

Neste livro, Parker ressalta que a noção de sensualidade e sexualidade é um dos pilares para a interpretação tanto do indivíduo quanto da sociedade no Brasil. Para o autor,

[...] os brasileiros consideram-se como seres sensuais não apenas em termos de sua individualidade (embora isso também seja 
importante), mas num nível social e cultural - como indivíduos sensuais, pelo menos em parte, em virtude de sua compartilhada brasilidade. E esta visão, por outro lado, desempenha papel importante na definição da natureza da vida brasileira em si própria e em relação ao mundo que a cerca, o mundo exterior, o mundo do estrangeiro (PARKER, 1991, p.22-23).

Essa concepção de mundo pode ser tomada pelos brasileiros tanto de um ângulo positivo (motivo de orgulho) como de um ângulo negativo, gerando constrangimento e vergonha, conforme o contexto. Entretanto, essa sexualidade exaltada tornou-se um dos mitos da cultura brasileira que dão significado tanto ao passado quanto ao presente do Brasil.

Além disso, nesta obra, Parker ressalta a importância de entender que em sociedades complexas como o Brasil existem múltiplos sistemas de significados sexuais,

[...] múltiplos subsistemas, em padrões recorrentes, embora díspares, conflitantes e, às vezes, até contraditórios, lógicas que, de alguma maneira, conseguiram entrelaçar e interpenetrar a tessitura da vida social (PARKER, 1991, p.14).

Estes subsistemas tornam-se pontos de referência a partir dos quais os(as) brasileiros(as) constroem e interpretam suas próprias experiências. Além disso, o autor ressalta a dificuldade em estabelecer ligações entre estes subsistemas devido à sua relação de coexistência e à sua inter-relação. Assim, não existiria uma uniformidade de crenças, significados e/ou lógicas a respeito da sexualidade, do gênero e dos papéis sexuais de homem e mulher no Brasil.

$\mathrm{O}$ autor aponta a permanência de alguns significados e lógicas sobre a vida sexual no Brasil contemporâneo. Entre estas permanências colocam-se os papéis de homem e mulher baseados na oposição entre atividade/passividade. Mas as classificações sexuais de homem e mulher não se apóiam mais apenas nessa oposição básica para a construção de identidades. Dentro de cada identidade existe uma variedade de figuras adicionais de possibilidades; para o homem existem as figuras de machão, corno e viado, e para a mulher as figuras de virgem, piranha e sapatão. O autor afirma: 
Essas figuras adicionais têm papéis secundários no elenco de personagens do drama sexual brasileiro, mas, de qualquer maneira, todos desempenham ações cruciais na construção do gênero na vida diária (PARKER, 1991, p.74).

O autor aponta a importância da figura do machão e do pai na sociedade brasileira, pois estes incorporam um conjunto de valores enraizados na estruturação do mundo de gênero no Brasil. Cria-se a imagem do homem em oposição à imagem da mulher e também a do veado e a do corno; estes são vistos como machos biológicos que falharam para corresponder ao ideal masculino (machão). O autor reafirma que o corno e o veado são considerados figuras negativas de masculinidade. Isso se torna mais evidente no caso do veado, pois, na oposição básica entre atividade e passividade, este assume o papel oposto ao de seu gênero, a passividade.

Já a figura da mulher é pautada também pela relação (positiva ou não) com as figuras de virgem, piranha e sapatão. A virgem é um símbolo de inocência e pureza representado no hímen, que marca a dominação masculina, a autoridade do pai e a honra da família. Para a sociedade brasileira o homem assume importância fundamental, porquanto é ele que transforma a virgem em esposa e mãe (dentro do casamento) ou em piranha (fora do casamento). Nesse painel da sexualidade brasileira, a piranha assume um papel negativo, uma vez que nega o controle social do homem sob seu comportamento sexual. Assim, a piranha destrói a família e assume um papel negativo, uma imagem oposta à da virgem.

Assim, nos vemos hoje diante de uma maior gama de papéis sexuais, mas a oposição básica entre "atividade e passividade" ainda se mantém. Além dessa permanência, Parker aponta também o duplo padrão de moralidade sexual no Brasil (mulher reprimida e controlada e homem incitado). Esse padrão se baseia na compreensão de uma diferença fundamental na natureza sexual de homens e mulheres. A sexualidade da mulher corre um curso natural e a do homem é inibida pelo contato com as mulheres (mãe, irmãs e avós no universo da casa) e precisa ser cultivada (por outros homens no universo da rua) para não se desviar. Segundo o autor, 
Dentro do contexto de concepções tão diferentes, então, o tratamento cultural da sexualidade feminina é muito claramente dirigido para o controle e a limitação. Baseia-se na economia simbólica de silêncio e ignorância, repressão e proibição. $\mathrm{O}$ tratamento da sexualidade masculina, ao contrário, deve ser a incitação e encorajamento, e um discurso quase constante sobre assuntos sexuais, dentro dos limites de grupos masculinos, e uma contínua e explícita educação sexual oferecida por homens mais velhos aos jovens (PARKER, 1991, p.103).

No entanto, Parker afirma que o século 20 foi marcado por um processo de modernização da vida sexual do Brasil no qual os discursos da medicina moderna foram transformados e expandidos não mais tratando a sexualidade pela dualidade saúde/doença e, respectivamente, como legítimo/ilegítimo, normal/desvio. Essa modernização da vida sexual no Brasil está ligada inextricavelmente ao processo de urbanização. Continua o autor,

Ao mesmo tempo, a impessoalidade relativa da vida urbana bem como o retrocesso do significado da família, da moralidade tradicional e da autoridade religiosa que acompanhou os processos de urbanização - abriu novos espaços na textura da sociedade para a reorganização dos valores sexuais e a reconstrução de suas práticas. Constantes mudanças na estrutura da família continuaram a solapar a força da autoridade patriarcal e começaram a afetar os papéis e status das mulheres na sociedade brasileira (PARKER, 1991, p.135).

Parker constata a importância da influência dos movimentos feministas e de liberação dos homossexuais na Europa e Estados Unidos para a construção do processo de modernização da vida sexual no Brasil, afirmando:

Uma preocupação anterior com a perversão deu lugar a um novo sentido de diversidade na vida sexual e a discussão da diversidade sexual foi focalizada menos nos pronunciamentos das autoridades morais, como padres e médicos, que nas opiniões variadas de um público de certa forma mais amplo (embora ainda constituído grandemente pela elite). Entretanto, para formar essas opiniões, a informação é crucial, e a essa tarefa de educar o público, a ciência 
moderna do sexo, como a chamaríamos, tem se dedicado amplamente (PARKER, 1991, p.138).

Os comportamentos antes considerados como não convencionais, ganham uma certa legitimidade, e passam a ser vistas como expressões de uma diversidade natural e não mais como perversões morais. O problema passa a ser visto como uma diversidade de comportamentos sexuais e não mais com preconceitos que as condenam como práticas anormais. Assim,

Práticas como a homossexualidade podem gradualmente ser resgatadas do domínio da perversão graças a uma ciência sexual mais esclarecida. $\mathrm{E}$ embora os preconceitos populares contra essas práticas dificilmente desapareçam, o debate em torno deles forçou um repensamento fundamental de muitas das assim chamadas formas de conduta desviada (PARKER, 1991, p.146).

Com o surgimento da AIDS, a discussão sobre a vida sexual no Brasil ganha relevo principalmente para pesquisas médicas, mas também para um discurso moral que toma a modernização da vida sexual como a responsável pela epidemia. Nas palavras de Parker (1991, p.147),

Tanto a doutrina religiosa como a moderna autoridade médica foram reafirmadas em face da Aids, à medida que acusações de pecado e doença surgiram outra vez na discussão de uma moléstia ligada à transmissão sexual e ao comportamento não convencional. Mas, ao mesmo tempo, no fim dos anos 80 , a emergente epidemia de Aids também deu lugar à reafirmação de doutrinas mais liberais. A Aids tornou-se cada vez mais um foco de políticas mais progressistas, veteranas do feminismo e movimentos homossexuais tornaram-se os principais ativistas da Aids e a luta contra a doença ocasionou o crescimento do movimento social comprometido com a modernização da moralidade sexual e a defesa da diversidade sexual.

\section{Considerações Finais}

Longe de atingir uma análise final e completa da obra CasaGrande \& Senzala, impossibilidade demarcada pelo caráter exploratório deste artigo, busquei delimitar como Gilberto Freyre ao 
deslocar o foco da questão de raça - como um fenômeno essencialmente biológico - para a questão da cultura, acaba promovendo o rompimento de diversos mitos e análises sobre a realidade cultural, social e sexual brasileira.

Através desta abordagem, Gilberto Freyre fornece um repensamento fundamental do problema da miscigenação enfatizando de maneira mais positiva a mistura de culturas e a criação de uma nova civilização nos trópicos, como resultado dessa mistura. Em Casa-Grande \& Senzala ele insiste em colocar a mistura racial como o elemento unificador da vida brasileira, contrariamente a outros autores que viam na miscigenação o produto da degeneração física que marcaria o povo brasileiro. Nas palavras dele,

À vantagem da miscigenação correspondeu no Brasil a desvantagem tremenda da sifilização. Começaram juntas, uma a formar o brasileiro - talvez o tipo ideal do homem moderno para os trópicos, europeu com sangue negro ou índio a avivar-lhe a energia; outra a deformá-lo. Daí certa confusão de responsabilidades; atribuindo muitos à miscigenação o que tem sido obra principalmente da sifilização (FREYRE, 2000, p.119).

Ao deslocar a degeneração física da mistura racial realizada aqui no Brasil para a infecção sifilítica, a análise freyreana sustenta a esperança de que os efeitos negativos desse processo de degeneração física possam ser minimizados ou mesmo, em última instância, sanados pela medicina incipiente.

Além disso, Freyre defende que a "intoxicação sexual" do Novo Mundo está ligada não à extrema luxúria das raças ameríndias e africanas, mas à própria essência da escravidão como instituição responsável pela permissividade e excesso sexual, bem como pela lassidão moral estabelecida no contato entre as três raças - ameríndia, portuguesa e africana - principais formadoras da população colonial.

Somando a isso, o autor de Casa-Grande \& Senzala ressalta a importância da tradição patriarcal para a compreensão das relações entre os gêneros, tendo a mulher seu lugar e suas ações marcadamente centradas na casa, na passividade e, o homem no mundo externo, na 
atividade. A mulher com sua sexualidade sempre restringida e vigiada e o homem com extrema liberdade sexual, criando aposições, criando masculinidade e feminilidade, dando, enfim, formas à vida sexual no Brasil.

Segundo Richard Parker, na atualidade essas formas de conceber a sexualidade e os papéis sexuais de homem e mulher se mantêm ganhando nuances e se diversificando em outros papéis secundários, tais como os de viado, de corno, de piranha e de sapatão. Estes novos papéis, entretanto vêm acrescentar mais figuras à antinomia atividade/ passividade e não modificá-la essencialmente.

Além disso, ainda permanece o mito do povo brasileiro como sendo extremamente sexualizado e sensual. E, esse caráter sexualizado da vida brasileira, segundo Parker, tem-se tornado motivo para olhares constrangidos e desconfiados que lançamos cotidianamente para nossa vida.

\section{Referências}

CRISTÓVÃO, Fernando Alves. A fiç̧ão de Gilberto Freyre como produto de sua obra sociológica. Ciência \& Trópico, Recife, v.12, n.2, p.195-210, jul./dez., 1984.

FREYRE, Gilberto. Casa-Grande \& Senzala. Rio de Janeiro: Record, 2000.

. Como e porque escrevi Casa-Grande \& Senzala. Brasília: Ed. Universitária, 1988

PARKER, Richard G. Corpos prazeres e paixões: a cultura sexual no Brasil contemporâneo. São Paulo: Ed. Best Seller, 1991.

REZENDE, Maria José. A otimização do passado e a idealização da mudança social em Gilberto Freyre. Revista de Ciências Humanas, Florianópolis, n.29, p.9-34, abr. 2001.

SEYFERTH, Giralda. Construindo a nação: hierarquias raciais e o papel do racismo na política de imigração e colonização. In: CHOR MAIO, M.; VENTURA SANTOS, R. (Org.) Raça, ciência e sociedade. Rio de Janeiro: Ed. Fiocruz/CCBB, 1996. p.41-58.

VILA NOVA, Sebastião. Cultura e sociedade em Gilberto Freyre. Ciência \& Trópico, Recife, v.19, n.2, p.311-326, jul./dez., 1991. 


\section{Abstract}

This is an article about the construction of sexuality in Brazil, based on the analysis of the book "Casa Grande \& Senzala," by Gilberto Freyre. The main theme of this work is the contribution of the mixing movement of the three main races that created the Brazilian population, and also the contribution of the Portuguese colonization process to the creation of a structure of sexuality based on permissive aspects, some times, and on a patriarchal model in other moments. I also analyse how some aspects of that sexuality (permissive/patriarchal) were kept and are still present in the Brazilian society nowadays.

Key words: race mixing; sexuality, permissivism; patriarchalism. 